Original Research Article

\title{
Synergistic effect of metformin and fenugreek on the lipid profile of type-II diabetic patients
}

\author{
Manmeet $\operatorname{Kaur}^{1 *}$, Narinder Singh ${ }^{2}$
}

${ }^{1}$ Department of Pharmacology, Kalpana Chawla Government Medical College, Karnal, Haryana, India

${ }^{2}$ Department of Pharmacology, Sri Guru Ram Das Institute of Medical sciences and Research, Amritsar, Punjab, India

Received: 21 June 2019 Accepted: 06 July 2019

*Correspondence to:

Dr. Manmeet Kaur,

Email: drmanmeet26@

hotmail.com

Copyright: (C) the author(s), publisher and licensee Medip Academy. This is an openaccess article distributed under the terms of the Creative Commons Attribution NonCommercial License, which permits unrestricted noncommercial use, distribution, and reproduction in any medium, provided the original work is properly cited.

\begin{abstract}
Background: Fenugreek is a traditional herb which has great relevance in the world since time immemorial due to its multifarious uses. Besides being a rich source of nutrition, it also finds place in the cure of certain pathological conditions. One of its highly beneficial effects is have been observed on the lipid profile of the hyperlipidemic patient. This study was thus undertaken to see the hypolipidemic effect of fenugreek seeds in patients of Type 2 Diabetes Mellitus (DM) as add-on therapy with metformin.

Methods: An open-labelled comparative study of 12 weeks duration was conducted on patients (randomly divided in 2 groups of 30 each) of Type 2 DM. Group 1 was given metformin $500 \mathrm{mg}$ twice a day while group 2 was given 500 $\mathrm{mg}$ of metformin along with fenugreek seed powder capsule, $1 \mathrm{gm}$ thrice a day. Evaluation for fasting lipid profile estimation was done at the beginning and at the end of the study. Student's t-test (paired and unpaired) was applied for statistical analysis.

Results: After 12 weeks of treatment, there was significant improvement in the lipid profile of both the groups. However, group 2, that received fenugreek along with metformin showed statistically greater improvement as compared to group 1 which received only metformin.

Conclusions: This study shows the beneficial effects of fenugreek seeds on lipid profile in patients of Type $2 \mathrm{DM}$ and can be used as an add-on therapy with metformin in controlling the lipid profile of Type $2 \mathrm{DM}$.
\end{abstract}

Keywords: Fenugreek, HDL cholesterol, LDL cholesterol, Metformin, Serum triglycerides, Total cholesterol, Type 2 diabetes mellitus

\section{INTRODUCTION}

Diabetes mellitus is syndrome with disordered metabolism and inappropriate hyperglycemia due to either a deficiency in insulin secretion or a combination of insulin resistance and inadequate insulin secretion to combat for the resistance. ${ }^{1}$ The disease may be associated with comorbid conditions like hypertension, coronary artery disease, peripheral and cerebral vascular disease. ${ }^{2}$

Diabetes mellitus is classified mainly as Type-1 Diabetes mellitus (Insulin-dependent diabetes ) and Type-2. Type-2 Diabetes mellitus (Non-insulin-dependent diabetes or
Adult-onset diabetes) constitutes about $90-95 \%$ of all the reported cases of diabetes. ${ }^{3}$

Type 2 Diabetes Mellitus patients are characterized by Dyslipidemia and often the term 'Metabolic Syndrome' is often used. ${ }^{4}$ This is characterized by low HDL-cholesterol, high serum VLDL-triglycerides, and elevation of LDL. These are often associated with a marked increase in cardiovascular risk. Diabetic Dyslipidemia has more atherogenic propensity in Type 2 Diabetes patients than the general dyslipidemic population. Thus, lowering the serum lipid levels will have great benefit in Type 2 Diabetes patients. ${ }^{5}$ 
Presently metformin has been incorporated in the early stage of management of Type $2 \mathrm{DM}$ as the first choice oral agent, along with appropriate diet control and lifestyle advice. ${ }^{6,7}$ It also has a role in preventing the progression of impaired glucose tolerance (IGT) stage to full-fledged Type 2 DM. $^{8}$ Metformin acts by activating cyclic AMPdependent protein kinase which causes the impairment of gluconeogenesis and also slows the absorption from the gut, with the additional role of reducing lipogenesis in adipose tissue and increasing fatty acid oxidation..$^{9-11}$

Fenugreek (Trigonella foenum graceum) belongs to the family of Papilionaceae-leguminosae.. The leaves and seeds, which mature in long pods, have been used extensively to prepare extracts and powders for medicinal uses. ${ }^{12}$ Fenugreek is reported to have anti-diabetic, antifertility, anticancer, anti-oxidant, immunomodulatory, anti-parasitic and hypocholesterolaemic, effects. ${ }^{13-18}$ Tannins, Carbohydrate, Glycosides, Phenols, Resins, Flavonoids, Alkaloid, Terpenes and Lignin are the main constituents of fenugreek. ${ }^{19}$ Lignin prevents the rapid uptake of glucose in the small intestine, slows gastric emptying, aids in blood sugar retention in diabetic patients and may also be effective in the treatment of hypercholesterolemia. ${ }^{20,21 .}$

Fenugreek seeds also increase the insulin sensitivity through the activation insulin signalling at an early stage in peripheral tissues and liver. ${ }^{21}$ The effect is brought by liver and lipid metabolism with up-regulation of certain enzymes and increase in the glycogen synthesis in the muscle and the liver. ${ }^{22-26}$ In addition, fenugreek enhances the peroxisome proliferator activated receptor $-\gamma(\operatorname{PPAR} \gamma)$ and promotes adipocyte differentiation and size reduction. ${ }^{27,28}$

Fenugreek also reduces the triglyceride content and mRNA expression levels of lipogenic genes. Thus, leading to down regulation of lipid synthesis as well as inhibiting lipid absorption. ${ }^{29,30}$ The estrogenic content of fenugreek also has a lipoid lowering effect by indirectly increasing the thyroid hormone. ${ }^{31}$

Though much work on the clinical efficacy of fenugreek seed powder has been done but till date no study has been undertaken to compare its clinical efficacy when used in combination it with metformin have been done in the Punjabi population.

The present study was therefore planned to explore the hypolipidemic effect of fenugreek seed powder when used with metformin and compare its effect with that of metformin used alone.

\section{METHODS}

This twelve weeklong, open, standard controlled and parallel randomized study involved 60 patients, of either sex, with Type 2 DM, fulfilling the inclusion criteria and attending the Medicine OPD at Sri Guru Ram Das
Charitable Hospital attached to Sri Guru Ram Das Institute of Medical Sciences and Research, Vallah, Amritsar. This study was conducted from September 2013 to Sept 2015. We distributed the patients randomly in two groups, Group 1 and Group 2 consisting of thirty patients each.

Informed Consent was taken from the patients to be included in this study and all the risks and the benefits were explained to each patient in their own language.

\section{Inclusion criteria}

Newly diagnosed Type-2 Diabetes Mellitus (Type 2 DM) patients of either sex, aged 30-70 years, having Fasting Blood Glucose $>126 \mathrm{mg} / \mathrm{dl}$ were included in the study.

\section{Exclusion criteria}

- Patients with Type-1 Diabetes Mellitus.

- Patients with history of ketoacidosis in the past.

- Patient with history of hypersensitivity to fenugreek seed powder.

- $\quad$ Patient with history of bleeding disorders.

- Patient with a history of surgery in the past six weeks.

- Pregnant females.

- Patient with history of drug abuse and steroid treatment

- Patient with history of cardiovascular diseases, uncontrolled diabetes, hepatic and renal disorder.

- Development of any clinical condition, necessitating change in treatment e.g. FBS $\geq 220 \mathrm{mg} \%$, any surgery required or any serious illness during the study period.

\section{Intervention}

Patients in Group 1 were given only Metformin $500 \mathrm{mg}$ twice a day after meals for 12 weeks and dose modifications were done according to the blood glucose levels. While patients in Group 2 were given fenugreek seed powder in a dose of 1 capsule of $1 \mathrm{gm}$ each thrice a day before meals along with Metformin $500 \mathrm{mg}$ twice a day after meals for 12 weeks. Dose modifications were done according to the blood glucose levels. Dose of Metformin was increased to a maximum of $1000 \mathrm{mg}$ twice a day and that of fenugreek seed powder to 2 capsules thrice a day.

The patients were investigated for lipid profile (HDL, LDL, Total Cholesterol and TG) at the beginning of the study (Day 0) and at the end of the study (after 12 weeks). Clinical examination with routine investigations was done. The base line lipid profile was obtained after a twelve hour overnight fast.

Lipid profile estimations were done in the Pharmacology department, Sri Guru Ram Das Institute of Medical Sciences and Research. The patients were advised to report immediately in case they developed any adverse reaction e.g. nausea, vomiting, abdominal pain, muscle ache, fever, 
weight gain, diarrhea, flatulence or any other type of side effect.

\section{Statistical analysis}

The results obtained were analyzed statistically for the significance using Student's ' $t$ ' test (paired and unpaired). Paired ' $t$ ' test was done to determine the significance within the groups and unpaired ' $t$ ' was done to determine the significance between the groups. The level of significance was determined as ' $p$ ' value with $p>0.05$ taken as not significant (NS) and $\mathrm{p}<0.05$ taken as significant (S) at 5\% significance level, $\mathrm{p}<0.01$ taken as significant(S) at $1 \%$ significance level and $\mathrm{p}<0.001$ taken as highly significant (HS).

\section{RESULTS}

Table 1 shows that decrease in serum Total Cholesterol levels was highly significant $(\mathrm{p}<0.001)$ in both the groups from day 0 to the end of study period (12 ${ }^{\text {th }}$ week). However, the analysis of mean percentage change of both the groups showed that greater reduction in Group 2 as compared to Group 1 (Figure 1).

Table 1: Serum total cholesterol levels $\left(\right.$ Mean \pm SD) day 0 and $12^{\text {th }}$ week in group 1 and group 2.

\begin{tabular}{|l|l|l|l|l|}
\hline \multirow{2}{*}{ Duration } & Group1 $(\mathbf{n}=\mathbf{3 0})$ & \multicolumn{2}{l}{ Group 2 $(\mathbf{n = 3 0})$} & \\
& Mean \pm SD & Mean change from baseline & Mean \pm SD & Mean change from baseline \\
\hline Day 0 & $200.96 \pm 29.37$ & -------- & $192.46 \pm 30.83$ & ---------- \\
\hline $12^{\text {th }}$ week & $194.03 \pm 29.03$ & $6.93 \pm 2.46^{\mathrm{HS}}$ & $173.767 \pm 25.07$ & $18.67 \pm 8.5^{\mathrm{HS}}$ \\
\hline
\end{tabular}

Table 2: Serum triglycerides levels $(M e a n \pm S D)$ on day 0 and $12^{\text {th }}$ week in group1 and group 2.

\begin{tabular}{|l|l|l|l|l|}
\hline \multirow{2}{*}{ Duration } & \multicolumn{2}{c}{ Group $1(\mathbf{n}=\mathbf{3 0})$} & \multicolumn{2}{l|}{ Group $2(\mathbf{n}=30)$} \\
& Mean \pm SD & Mean change from baseline & Mean \pm SD & Mean change from baseline \\
\hline Day 0 & $188 \pm 39.40$ & ---------- & $161.003 \pm 48.77$ & ---------- \\
\hline $12^{\text {th }}$ week & $181.9 \pm 38.67$ & $6.2 \pm 2.63^{\mathrm{HS}}$ & $144.86 \pm 35.57$ & $16.15 \pm 19.25^{\mathrm{HS}}$ \\
\hline
\end{tabular}

Table 3: Serum HDL levels (Mean \pm SD) on day 0 and $12^{\text {th }}$ week in group 1 and group 2.

\begin{tabular}{|l|l|l|l|l|}
\hline \multirow{2}{*}{ Duration } & Group1 $(\mathbf{n}=\mathbf{3 0})$ & \multicolumn{2}{l|}{ Group 2 $(\mathbf{n = 3 0})$} \\
\hline Day 0 & Mean \pm SD & Mean change from baseline & Mean \pm SD & Mean change from baseline \\
\hline $12^{\text {th }}$ week & $40.83 \pm 4.33$ & --------- & $44.12 \pm 5.38$ & --------- \\
\hline
\end{tabular}

Table 4: Serum LDL levels (Mean \pm SD) on day 0 and $12^{\text {th }}$ week in Group 1 and group 2.

\begin{tabular}{|l|l|l|l|l|}
\hline \multirow{2}{*}{ Duration } & \multicolumn{1}{c}{ Group $1(\mathbf{n}=\mathbf{3 0})$} & Group $2(\mathbf{n}=30)$ & \\
& Mean \pm SD & Mean change from baseline & Mean \pm SD & Mean change from baseline \\
\hline Day 0 & $122.5 \pm 27.08$ & ------ & $116.06 \pm 29.88$ & -------- \\
\hline $12^{\text {th }}$ week & $116.06 \pm 27.01$ & $6.32 \pm 3.08^{\mathrm{HS}}$ & $99.19 \pm 25.26$ & $16.87 \pm 25.26^{\mathrm{HS}}$ \\
\hline
\end{tabular}

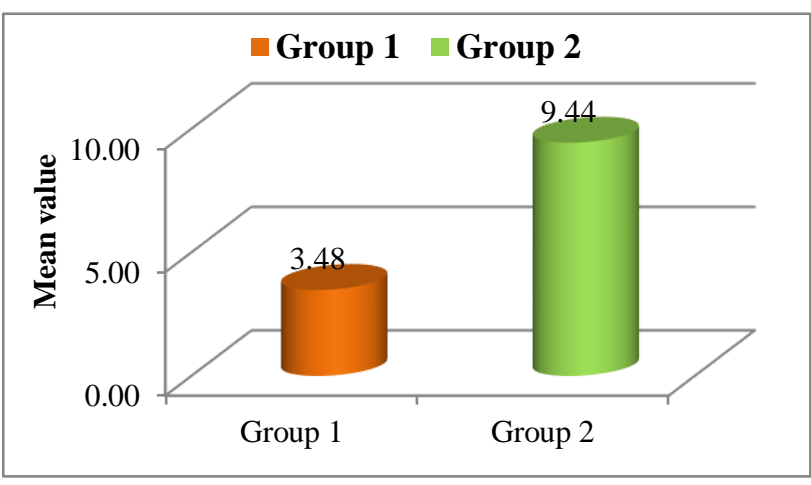

Figure 1: Mean percentage change in total cholesterol levels in group 1 and 2.

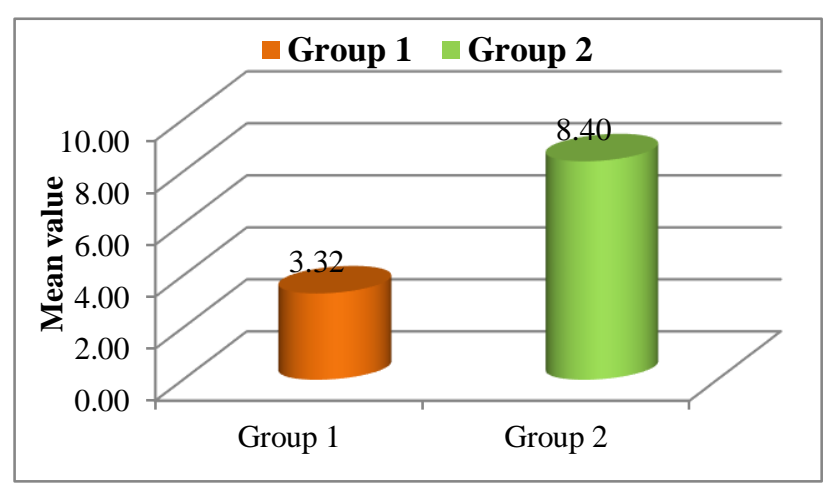

Figure 2: Mean percentage change in serum triglycerides levels in group 1 and 2. 


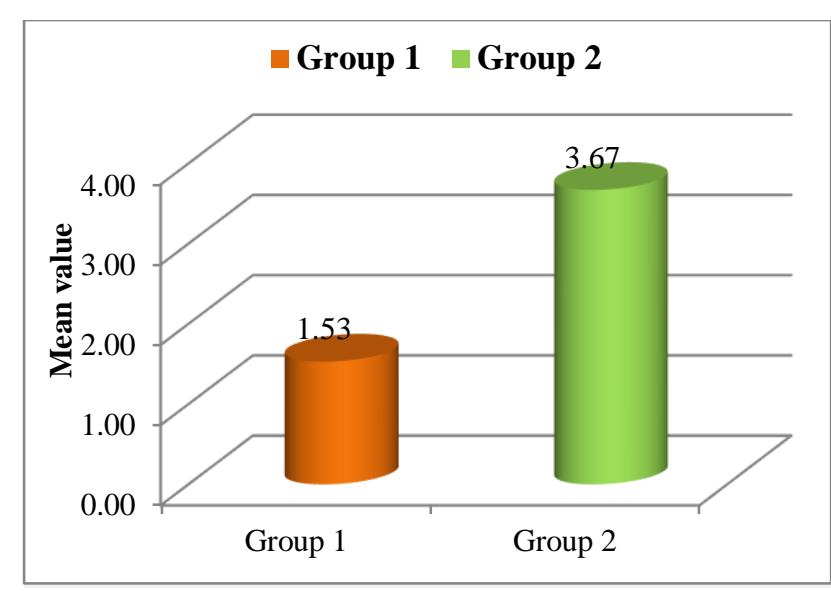

Figure 3: Mean percentage change in serum HDL-C levels in group 1 and 2.

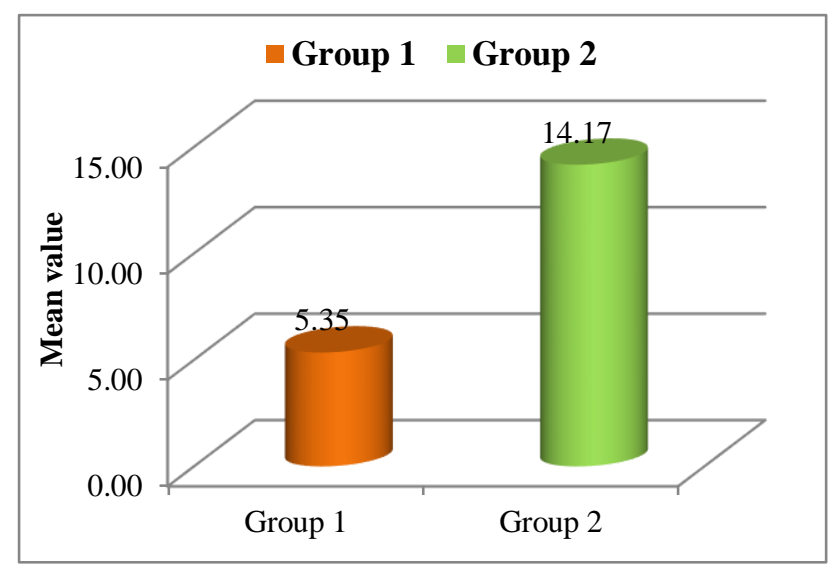

Figure 4: Mean percentage change in serum LDLcholesterol levels in group 1 and 2.

Baseline mean serum Triglycerides levels were less in Group $2(161.003 \pm 48.77 \mathrm{mg} / \mathrm{dl})$ as compared to Group 1 $(188 \pm 39.40 \mathrm{mg} / \mathrm{dl})$. However, there was highly significant $(\mathrm{p}<0.001)$ reduction in serum Triglycerides in both the groups at the end of 12 weeks. Group 2 however showed a statistically greater reduction as compared to Group 1 (Table 2, Figure 1).

There was a significant $(\mathrm{p}<0.05, \mathrm{p}<0.01)$ increase in Serum HDL levels in both the groups $(\mathrm{p}<0.01)$ from day 0 till the end of $12^{\text {th }}$ week, with Group 2 showing better improvement in serum HDL levels (Table 3, Figure 3).

There was a highly significant $(\mathrm{p}<0.001)$ decrease in serum LDL levels in both the groups from day 0 to the twelfth week in both the groups. Mean percentage reduction in serum LDL levels was more in Group 2 than in Group 1 (Table 4, Figure 4).

\section{DISCUSSION}

The Type 2 DM patients with mild fasting hyperglycemia usually have associated hyperlipidaemia. Many factors influence plasma lipid profile in Type 2 DM patients.
These include genetic factors, concomitant diseases, lifestyle and many more factors. This alteration in lipid levels is one of the causative factors of macrovascular complications of Type $2 \mathrm{DM} .^{32-34}$

The present study was thus undertaken to assess the lipid levels in newly diagnosed Type $2 \mathrm{DM}$ patients and also to evaluate the add on effect of fenugreek on metformin on lipid levels of these patient.60 newly diagnosed Type 2 DM were included in the study. They were randomly divided in 2 groups of 30 each. Group 1 received Metformin $500 \mathrm{mg}$ twice a day after meals for 12 weeks whereas Group 2 patients were given metformin $500 \mathrm{mg}$ twice daily after meals along with fenugreek seed powder in a dose of 1 capsule thrice a day (1 capsule containing $1 \mathrm{gm}$ of fenugreek seed powder) for the same duration. Measurement of Fasting lipid profile (HDL, LDL, Total Cholesterol and TG) was done at the beginning of study (Day 0) and at the end of study (at the end of 12 weeks).

There was a significant reduction in Total Serum Cholesterol levels in both the groups $(\mathrm{p}<0.01)$. However, the mean percentage reduction in group 2 was greater than in group 1. Similarly, there was a greater reduction serum Triglycerides and serum LDL levels in group 2 as compared to group 1 at the end of $12^{\text {th }}$ week. However, this reduction was highly significant in both the groups. Whereas there was a significant increase in serum HDL levels in both group 1 and group 2. These finding were very much in consonance with a study conducted by Kumar et al. It was undertaken to evaluate the effect of fenugreek seeds Type $2 \mathrm{DM}$ patients with dyslipidemia for a period of 8 weeks. The patients were divided into 2 groups. One received solely fenugreek seed powder and other group received oral hypoglycemic and hypolipidemic drugs. The lipid profile were recorded at the beginning and at the end of the study. This was pattern of evaluation was followed in this study. But the duration of our study however differed (12 weeks' duration). There was a significant reduction in total cholesterol, triglycerides and LDL cholesterol. HDL cholesterol levels in the patients showed a significant increase $(\mathrm{p}<0.001){ }^{35}$

Fenugreek seeds lower the serum triglycerides, total cholesterol and LDL cholesterol. This is due to sapogenins, which increase biliary cholesterol excretion in turn leading to lowered cholesterol levels. The lipid lowering effect of fenugreek might also be attributed to oestrogenic constituent, indirectly increasing thyroid hormone. ${ }^{36}$ The cholesterol lowering activities is also attributed to fibre-rich gum portion of the seeds that reduces the hepatic synthesis of cholesterol. It is likely that both mechanisms contribute to the overall effect. ${ }^{37}$

Muraki et al. evaluated the blood samples, liver tissue, intracapsular brown adipose tissue, epididymal white adipose tissue and fecal samples of fenugreek seed powder treated Hyperglycemic rats. The findings of decrease in blood glucose, total cholesterol and triglycerides in addition to the decrease in weight of the adipose tissues, 
presence of increased bile acids in the fecal samples are suggestive that fenugreek seed powder inhibited lipid accumulation in liver by increasing lipid excretion in feces. $^{24}$

As described Ramesh Babu et al. conducted a study on alloxan induced diabetic rats. They were treated with water extract of fenugreek seeds for 21 day. There was highly significant reduction in serum cholesterol, Triglycerides and LDL cholesterol. And there was a significant elevation in HDL levels $(p<0.001)$. This is very much in confirmation in this studies. ${ }^{36}$

To further support the fact that 4-hydroxyisoleucine (4HOIle) was responsible for the hypolipidemic effect, studies were carried out by Haeri et al. Type I diabetes, streptozotocin-treated rats along with compared to normal rats were used for the experiment. Treatment of diabetic rats with daily doses of $4 \mathrm{HO}-\mathrm{Ile}$ at $50 \mathrm{mg} / \mathrm{kg} /$ day for 4 weeks restored levels of lipids (cholesterol, HDL, LDL and triglycerides) to normal levels. ${ }^{38}$ This supports the fact of our study which inferred that fenugreek besides had a strong hypolipidemic effect, resulting in the reduction of total cholesterol, Triglycerides and LDL levels and elevation in HDL levels.

Further support to the present study was given by study carried out by Xue et al. in which Streptozotocin induced diabetic rats treated with combination a fenugreek extract (low dose, middle dose and high dose) and metformin hydrochloride for a duration of 6 weeks. Highly significant reduction occurred in blood glucose, total cholesterol, Triglycerides and HDL levels in a dose dependent manner. ${ }^{39}$

Shrivastava et al. too in their study besides demonstrating the hypoglycaemic effect of fenugreek observed that administration of fenugreek seed powder to Type 2 DM patients resulted in significant reduction in total cholesterol, Triglycerides and LDL levels at the end of 45 days. $^{40}$

\section{CONCLUSION}

The present study demonstrated that when fenugreek seed is along with metformin in type 2 Diabetes Mellitus patients had a beneficial effect on the lipid profile. Thus, fenugreek seed powder holds a favourable future as far as the treatment of type 2 Diabetes patients is concerned as regards the lipid profile.

Funding: No funding sources Conflict of interest: None declared

Ethical approval: The study was approved by the Institutional Ethics Committee

\section{REFERENCES}

1. Maharani U. Diabetes Mellitus \& Hypoglycemia . In: Papadakis MA, McPhee SJ, eds. Current Medical
Diagnosis and Treatment. $56^{\text {th }}$ ed. New York: McGraw Hill; 2017:1210-58.

2. American Diabetes Association. Diagnosis and Classification of Diabetes Mellitus. Diabetes Care. 2004;27(1):5-11.

3. American Diabetes Association. Diagnosis and Classification of Diabetes Mellitus. Diabetes Care. 2012;35(1):65-71.

4. Martha M, Nolte Kennedy MS. Pancreatic hormone and anti-diabetic drugs. In: Katzung BG, Masters SB, Trevor AI, eds. Basic and Clinical Pharmacology. $12^{\text {th }}$ ed. New Delhi: Tata McGraw Hill; 2012:753-67.

5. Guillausseau PJ, Massin P, Charles MA. Glycemic controland development of retinopathy in type 2 Diabetes Mellitus: a longitudinal study. Diabetes Med. 1998:15(2):151-5.

6. Davidson MB, Diabetes Mellitus: Diagnosis and Treatment. 21 NewYork, NY. Churchill Livingstone. 2010:795-835.

7. Management of Diabetes. A national clinical guideline. Edinburgh; Scottish Intercollegiate Guideline Network. 2010 Mar [cited 2013 Nov].Available at: www.sign.ac.uk/guidelines/fulltext/50/index. html.

8. De Fronzo RA. Pharmacological therapy for type 2 diabetes mellitus. Ann Intern Med. 1991;131(4):281303.

9. Tripathi KD. Essentials of Medical Pharmacology. $7^{\text {th }}$ ed. New Delhi: Jaypee Brothers Medical Publisher's; 2013:258-81.

10. Zhou G, Myers R, Li Y, Chen Y, Shen X, FenykMelody J, et al. Role of AMP-activated protein kinase in mechanism of metformin action. J Clin Investigat. 2001;108(8):1167-74.

11. Gunton JE, Delhanty PJ, Takahashi SI, Baxter RC. Metformin rapidly increases insulin receptor activation in human liver and signals preferentially through insulin-receptor substrate-2. J Clin Endocrinol Metab. 2003;88(3):1323-32.

12. Shojaii A, Goushegir A, Dabaghian FH, Abdollahi M, Huseini HF. Herbs and herbal preparations for glycemic control in diabetes mellitus (a systematic review). J Medi Plants Res. 2011;5(16); 3846-55.

13. Kochhar A, Nagi M. Effect of supplementation of traditional medicinal plants on blood glucose in noninsulin dependent patients: a pilot study. J Med Food. 2005;8(4);545-9.

14. Basch E, Ulbricht C, Kuo G, Szapary P, Smith, M. Therapeutic applications of fenugreek. Altern Med Rev. 2003;8(1):20-7.

15. Gupta A, Gupta R, Lal B. Effect of Trigonella foenumgraecum (fenugreek) seeds on glycaemic control and insulin resistance in type 2 diabetes. J Assoc Physicians India. 2001;49:1057-61.

16. Sharma RD. Hypocholesterolemic activity of fenugreek (Trigonella foenum graecum)-an experimental study in rats. Nutr Rep Int. 1984;(30):221-31.

17. Tripathi UN, Chandra D. The plant extracts of Momordica charantia and Trigonella foenum graecum 
have antioxidant and anti-hyperglycemic properties for cardiac tissue during diabetes mellitus. Oxid Med and Cellular Longevity. 2009;2(5):290-6.

18. Tripathi S, Maurya AK, Kahrana M, Kaul A, Sahu RK. Immunomodulatory property of ethanolic extract of Trigonella foenum-graeceum leaves on mice. Der Pharm Lett. 2012;4(2):708-13.

19. Tiran D. The use of fenugreek for breast feeding women. Complement Ther Clin Pract. 2003;9(3):1556.

20. Sauvaire Y, Petit P, Broca C, Manteghetti M, Baissac Y, Fernandez-Alvarez Jl. Hydroxyleucine, a novel potentiator of insulin secretion. Diabetes. 1998;47(2):206-10.

21. Kumar VS, Rama Rao DKA, Mohanty S. Comparative study of fenugreek seeds on glycemic index in high and medium dietary fibre containing diets in NIDDM Patients. NJIRM. 2011;2(3):29-37.

22. Mullaicharam AR, Deori G, Maheswari U. Medicinal Values of Fenugreek-A Review. Res J Pharmaceut Biol Chem Scie. RJPBCS. 2013;4(1):1304-13.

23. Broca C, Gross R, Petit P Sauvaire Y, Manteghetti M, M Tournier, Masiello P, R Gomis Ribes R 4Hydro,xyisoleucine: experimental evidence of its insulinotropic and antidiabetic properties. Amer J of Physiol-Endocrinol Metab. 1999;277(4):617-23.

24. Mohammad S, Taha A, Akhtar K, Bamezai RN, Baquer NZ. In vivo effect of Trigonella foenum graceum on the expression of pyruvate kinase ,phosphoenolpyruvate carboxykinase and distribution of glucose transporter (GLUT4). Can J Physiol Pharmacol. 2006;84:647-54.

25. Raju J, Gupta D, Rao AR, Yadava PK, Baquer NZ. Trigonella foenum graceum(fenugreek)seed powder improves glucose homeostasisin alloxan diabetic rat tissues by reversing the altered glycolytic, gluconeogenic and lipogenic enzymes. Mol Cell Biochem. 2001;224:45-51.

26. Mohammad S, Taha A, Akhtar K, Bamezai RN, Baquer NZ. Lower doses of vandate in combination with trigonella restore altered carbohydrate metabolosim and antioxidant status in alloxan-diabetic rat. Clin Chem Acta. 2004;342(1-2):105-14.

27. Madder LZ, Thorn R. Dietery Fibre. Prog Food Nutr Sci. 1987;11(2):153-74.

28. Baquer NZ, Kumar P, Taha A, Kale RK, Cowsik SM, McLean P. Metabolic and molecular action of Trigonella foenum-graecum (fenugreek) and trace metals in experimental diabetic tissues. J Biosci. 2011;36(2):383-96.

29. Muraki E, Hayashi Y, Chiba H, Tsunoda N, Kasono K. Dose-dependent effects, safety and tolerability of fenugreek in diet-induced metabolic disorders in rats. Lipids Health Dis. 2011;10(1):240.
30. Ramadan G, El-Beih NM, Abd El-Kareem HF. Antimetabolic syndrome and immunostimulant activities of Egyptian fenugreek seeds in diabetic/obese and immunosuppressive rat models. $\mathrm{Br} \mathrm{J}$ Nutr. 2010;105(7):995-1004.

31. Vats V, Yadav SP, Grover JK. Effect of T. foenumgraecum on glycogen content of tissues and the key enzymes of carbohydrate metabolism. J Ethnopharmacol. 2003;85(2-3):237-42.

32. Abbate SL, Brunzell JD. Pathophysiology of hyperlipidemia in diabetes mellitus. J Cardiovasc Pharmacol. 1990;16(9):1-7.

33. Turner RC, Millns H, Neil HA, Stratton IM, Manley SE, Matthews DR, Holman RR. Risk factors for coronary artery disease in non-insulin dependent diabetes mellitus: United Kingdom Prospective Diabetes Study (UKPDS: 23) BMJ. 1998;316(7134):823-828.

34. Taskinen MR. Diabetic dyslipidaemia: from basic research to clinical practice. Diabetologia. (2003);46(6):733-49

35. Kumar K, Kumar S, Datta A, Bandyopadhyay A. Effect of fenugreek seeds on glycemia and dyslipidemia in patients with type 2 diabetes mellitus. Int J Med Sci Public Health. 2015;4(7):997-1000.

36. Babu K, Yogesh, Raghvendra HL, Kantikar SM, Prakash KB. Antidiabetic and histopathological analysis of fenugreek extract and alloxan induced diabetic rats. Int $\mathbf{J}$ Drug Dev\& Res. 2010 Apr;2(2):356-64

37. Kumar A, Kumar B, Kumari S. Diabetes Mellitus and its Herbal Treatment. Int J Biol Med Res. 2014;5(3):4180-5.

38. Haeri MR, Limaki HK, White CJ, White KN. Noninsulin dependent anti-diabetic activity of (2S, 3R, 4S) 4-hydroxyisoleucine of fenugreek (Trigonella foenum graecum) in streptozotocin-induced type I diabetic rats. Phytomedicine. 2012 May 15;19(7):571-4.

39. Xue WL, Li XS, Zhang J, Liu YH, Wang ZL, Zhang RJ. Effect of Trigonella foenum-graecum (fenugreek) extract on blood glucose, blood lipid and haemorrogical properties in streptozotocin-induced diabetic rats. Asia Pac J Clin Nutr. 2007;16(1):422-6.

40. Shrivastava RK, Meena M,Verma M, Kosta S, Kumar R. A prospective study to see the effect of fenugreek seeds powder as a hypoglycemic agent on type 2 Diabetes. Int J Bioassays. 2013;2(10):1344-8.

Cite this article as: Kaur M, Singh N. Synergistic effect of metformin and fenugreek on the lipid profile of type-II diabetic patients. Int J Basic Clin Pharmacol 2019;8:1738-43. 